\title{
Últimas hipótesis sobre el Conde de Lautréamont y Dalí: escritos y obra plástica
}

\section{Last hypothesis about Count of Lautréamont and Dalí: written and art works}

\author{
Iván Moure Pazos \\ Universidad de Bolonia y Fundación Pedro Barrié de la Maza \\ ivan.menes@yahoo.es
}

Recibido: 10 de mayo de 2011

Aprobado: 27 de julio de 2011

\begin{abstract}
Resumen
El presente artículo trata de establecer vínculos entre el Conde de Lautréamont y Salvador Dalí a través de su iconografía. Desde el momento en que el surrealismo se propone invocar al Conde, la influencia de éste será un enorme agujero negro del que muy pocos lograrán desasirse. El caso de Dalí se erigirá como uno de los tributos más prolíficos e interesantes de este diálogo.

Palabras Clave: Lautréamont, Dalí, Les Chants de Maldoror.
\end{abstract}

Moure Pazos, I. 2011: Últimas hipótesis sobre el Conde de Lautréamont y Dalí: escritos y obra plástica. Arte, Individuo y Sociedad, 24(1), 39-57

\begin{abstract}
The article tries to settle bonds between Lautréamont Count and Salvador Dalí through their iconography. Since the surrealist movement proposes to invoke the Count, his influence is going to become an enormous black hole of wich only a few ones will be able to let go of. Dali's work will be elevated as one of the most prolific and interesting tributes to this dialogue.
\end{abstract}

Key Words: Lautréamont, Dalí, The songs of Maldoror.

Moure Pazos, I. 2011: Last hypothesis about Count of Lautréamont and Dalí: written and art works. Arte, Individuo y Sociedad, 24(1), 39-57

Sumario: 1. Introducción, 2. El Conde de Lautréamont en la obra escrita de Dalí: diarios, poesía y guiones cinematográficos, 3. Los objetos lautreamontianos: paraguas y máquinas de coser, 4 . El bestiario lautreamontiano: del canto del cisne al cerdo como mímesis maldororiana, 5. Conclusiones. Referencias 


\section{Introducción}

Hace ya algún tiempo Lourdes Cirlot, comentaba en su artículo "Salvador Dalí y sus influencias" (2004):

[...] no existe ninguna obra en la que se aborde la cuestión de las herencias y filiaciones perceptibles en la obra de Dalí a lo largo de toda su trayectoria artística. Pese a ser evidente que, en muchas ocasiones, el artista catalán tomó elementos diversos de la obra pictórica o escultórica de artistas de otras épocas, en la actualidad no existe todavía ningún estudio completo publicado que profundice en la iconografía daliniana, con objeto de desvelar cuáles pudieron ser las fuentes de sus complejas manifestaciones artísticas [...] Además, es importante señalar que tampoco se han establecido relaciones directas entre determinadas fuentes escritas y la pintura de Salvador Dalí. A lo sumo se señalan algunos textos que el propio Dalí nunca tuvo inconveniente en revelar, pero no se establecen las pertinentes conexiones. Por ejemplo, la conocida obra del Conde de Lautréamont, Los Cantos de Maldoror, constituyó el punto de partida para la realización de una importante serie de grabados de Dali en 1933, pero no existen análisis profundos que relacionen los textos con las imágenes. ¿Por qué Dali decidió resolver iconográficamente de un modo determinado sus grabados dedicados a Lautréamont y no de otro? (Cirlot, 2004) ${ }^{1}$

Por esas mismas fechas, y con motivo del año Dalí 2004, surgirán nuevas y refrescantes aportaciones entorno a la figura del pintor y su obra. Más allá de biografías tediosas, estudios trillados, o anécdotas mediáticas, afloran un sin fin de estudios centrados en el Dalí más complejo e intelectual. Tasar la verdadera magnitud de un artista tan versátil y polimórfico, pasaba directamente por Lautréamont -pseudónimo de Isidore Ducasse- y muchos así lo percibieron. La primera autora en comprenderlo fue Silvia Muñoz D'imbert, en su estupendo artículo "Les Chants de Maldoror: la construcción de la máquina de lectura", para el catálogo, Dalí: afinidades electivas (2004), en el cual, se esclarecen las "herencias y filiaciones perceptibles" de Cirlot:

Sin duda observando los grabados de Les Chants de Maldoror, nos hallamos frente al encuentro de la "máquina pictórica" de Dalí y la "máquina de lectura" de Ducasse, las cuales, habiendo traspasado sus propios límites, han conseguido unirse en otro nivel, metalingüistico y metapictórico, en el que se lleva a cabo la gran revelación radical de la imagen. (D'imbert, 2004)

La relación Ducasse-Dalí, comenzaba a desgajarse cobrando protagonismo en los mejores repertorios iconográficos del momento. Las alusiones de Fèlix Fanés (2003), Agustín Sánchez Vidal (2003), o Dawn Ades (2004), aunque someras, fueron sintomáticas de este empeño. No tardarían en aparecer estudios específicos sobre la filiación daliniana con Lautréamont. En esta línea, se sucedieron -con mayor o menor fortuna- diversos artículos, como el "Salvador Dalí a golpe de Lautréamont" (2006) de Raúl Herrero, en el que se enumeran algunos de los vínculos formales entre Dalí y Ducasse, o la alusión ficcionada sobre Dios que, Fernando Butazzoni realiza en su "Luz de arriba, luz de abajo" (2006). En otra categoría, se inscribe el trabajo que, desde hace algún tiempo, viene desarrollando Pilar Parcerisas entorno a este diálogo, y que materializará en su magistral artículo "Dalí y Ducasse. La sombra de Maldoror" 
(2010); una revisión de su conferencia "Dalí et Lautréamont" para el VIII Colloque international sur Lautréamont (2006), ofrecida esta vez, para el actual catálogo de la exposición Salvador Dalí. Les Chants de Maldoror. 1934. ${ }^{2}$

En dicho artículo, Parcerisas, establece una serie de atrevidas e ingeniosas interrelaciones entre Lorca, Maldoror, Lacan y Dalí, para esclarecer el diálogo entre Lautréamont y el pintor: "Será preciso retener esta imagen paranoica cuádruple: ¡Dalí y Lorca, Maldoror y Olé!". (Parcerisas, 2010). Para el mismo catálogo, y desde una óptica más formalista, queremos reseñar los trabajos de Juliette Murphy, "Les Chants de Maldoror: documentación y proceso creativo" (2010), y de Elisa María Díaz González "Aguafuerte y Heliograbado: consideraciones entorno a Les Chants de Maldoror" (2010), en los que se deja constancia rigurosa de todos aquellos aspectos formales relativos a la obra del pintor (documentación, procesos creativos, técnicas...)

En los últimos años, han aflorado varios estudios que afianzan el vínculo entre Lautréamont y Dalí, especialmente centrados en las filiaciones más evidentes entre el pintor catalán y el poeta francés. Estos son los estudios relacionados con las ilustraciones que Dalí realiza en 1934 para Les Chants de Maldoror. Sin embargo, creemos que la relación entre ambos artistas va más allá de una mera correspondencia explícita y, ampliar tablas explicativas sobre este fecundo diálogo, merece un estudio más detallado. A continuación, ofrecemos algunas pistas para comprender, de una manera pormenorizada, la alucinada conversación fraguada entre sendos artistas. Para ello, he estructurado el artículo en tres apartados:

- El Conde de Lautréamont en la obra escrita de Dalí: diarios, poesía y guiones cinematográficos.

- Los objetos lautreamontianos: paraguas y máquinas de coser.

- El bestiario lautreamontiano: del canto del cisne al cerdo como mímesis maldororiana.

\section{El Conde de Lautréamont en la obra escrita de Dalí: diarios, poesía y guiones cinematográficos}

Sabemos por Ian Gibson que Dalí leyó a Lautréamont en la residencia de estudiantes de Madrid, probablemente por influjo directo de Lorca, o indirecto de Rubén Darío (Gibson, 2004) ${ }^{3}$ A partir de entonces, la obsesión de Dalí por el Conde fue tal que en 1937 -tras ilustrar la célebre obra de Lautréamont, Les Chants de Maldoror- realizará un retrato de Ducasse valiéndose de su método paranoico-crítico (Hubert, 1988). El método consistiría en alcanzar el acto creativo a través de la interpretación crítica del proceso paranoico, pintando de modo realista el pensamiento irracional; sistema que se alejaba de las consignas automatistas del grupo surrealista. ${ }^{4}$ En dicha obra, Dalí insistirá en el enigma ducassiano, mediante la representación de un rostro imaginario que se debate entre la luz y la sombra, polarizando el claro-oscuro, no como artificio plástico, sino simbólico, aludiéndose, a lo desconocido, que es lo mistérico en Lautréamont. Con ello, Dalí dotará de rostro a su más oscura obsesión, quizás la más salvaje de sus primeros años. Y es que, en efecto, todo aquel que desee zambullirse entre las más de diez mil páginas escritas por el autor, se encontrará, no con poca 
asiduidad, con la sombra del Conde, ora en formato de encomio directo, ora reviviéndolo en futuribles imprecaciones, ora agazapado en ese vehicular paranoico-crítico, o simplemente tributado como álter ego en sus diarios cotidianos.

Van a ser, por lo tanto, muchas las fuentes por las que permee el fantasma de Lautréamont, de entre las cuales reseñaremos las más esenciales como representativas en la vida de Dalí. En la intimidad de sus diarios es donde mejor apreciaremos ese germen que, como peremne muérdago, pervivirá a lo largo de toda su vida. Más adelante, una vez oficializado el contrato, Dalí se tornará esquivo, complicando su relación con Ducasse, hecho que redundará en un sin fín de proyectos frustrados y utópicos. Allí nos encontraremos con un Dalí impotente, incapaz de materializar el verso ducassiano.

...Algunos de los documentos más fiables a la hora de analizar la vida de Salvador Dalí son sin duda sus escritos autobiográficos: Un diario (1919-20), The Secret life of Salvador Dalí (1942), Journal d'un genie (1962), Les passions selon Dalí (1968) y Comment on devient Dalí (1973). En ellos, Dalí se muestra asímismo como Maldoror -el héroe de la novela de Lautréamont- un personaje que practica el mal por el mal. Es así como el autor narra la historia de un admirador, que pobre, pide consejo al artista a fin de mejorar su fortuna. El hombre rompe a llorar y Dalí le sugiere como solución el suicidio. Entretanto, éste divisa un bulto blanco que cae desde lo alto de un edificio y que el autor identifica con Maldoror, aclarándonos posteriormente que aquella sombra habíase cernido sobre su vida, y en consecuencia, sobre sus actos de perversa maldad (Dalí, 2003a). A partir de entonces, las víctimas serán muchas y variopintas. Ciegos, niños, animales o ancianos, sufrirán las malas artes de un Dalí poseído por el maléfico espíritu maldororiano (Sánchez, 2003). Más adelante, Dalí no duda en jactarse de la compra de un esmoquin en una sastrería de la calle Vivienne, lugar de residencia de Isidore Ducasse ${ }^{5}$, como colofón final a ese juego mimético de personalidades. ${ }^{6}$

Otras veces, tras ser expulsado del grupo surrealista, Dalí utilizará a Lautréamont para legitimarse, pues, la exhibición de sangre y excrementos- motivo por el cual fue desterrado- nunca podría ser censurable desde una óptica lautreamontiana (Dalí, 2003b), o sádicamente batailleana. ${ }^{7}$ Esta doble traición será entendida por Dalí como el acercamiento definitivo hacia esa deidad llamada Lautréamont. Afianzado el vínculo y con el beneplácito de su maestro, el autor ya no vacilará a la hora de blasfemar contra Dios, abofetear a jóvenes (Dalí, 2003c), o incluso rendir culto a Ducasse con innumerables orgías de carne y sangre, en las que el mismísimo Dalí dispondrá minuciosamente el ceremonial. Saciado de tanto hedonismo, el autor extasiado, se retiraba a su apartamento, situado nuevamente en la calle Vivienne (Dalí, 2003c). Posteriormente -sobre todo en la etapa Americana- estos tributos irán perdiendo pornografía y ganando delirio, a fin de no escandalizar a las mentes bienpensantes, que eran además las que, por entonces, financiaban la obra del artista. De todas formas, en todos ellos, nunca faltaron decorados alusivos al Conde (paraguas, máquinas de coser), ya fuese en ponibles trajes u ordinaria decoración (Dalí, 2003c)

Cimentada la presencia lautreamontiana en la cotidianeidad de los diarios de Dalí, no será extraño encontrárnoslo de nuevo en su polifacética obra literaria. Una obra bastísima que nace de múltiples voracidades interpretativas. Es así como su can- 
to ...un joven de aspecto perfectamente normal, pero que pese a su insignificancia podría ser tomado por el símbolo de la apasionada y turbulenta poesía.., balizará el sendero de sus preferencias poéticas, al encomiar -casi plagiar- la siguiente estrofa lautreamontiana donde tiene lugar una transformación archimboldesca (Dalí, 2003d):

Je suis sale. Les poux me rongent. Les pourceaux, quand ils me regardent, vomissent. Les croûtes et les escarres de la lèpre ont écaillé ma peau, couverte de pus jaunâtre. Je ne connais pas l'eau des fleuves, ni la rosée des nuages. Sur ma nuque, comme sur un fumier, pousse un énorme champignon, aux pédoncules ombellifères. Assis sur un meuble informe, je n'ai pas bougé mes membres depuis quatre siècles. Mes pieds ont pris racine dans le sol et composent, jusqu'à mon ventre, une sorte de végétation vivace, remplie d'ignobles parasites, qui ne dérive pas encore de la plante, et qui n'est plus de la chair. Cependant mon cour bat. Mais comment battrait-il, si la pourriture et les exhalaisons de mon cadavre (je n'ose pas dire corps) ne le nourrissaient abondamment? Sous mon aisselle gauche, une famille de crapauds a pris résidence, et, quand l'un d'eux remue, il me fait des chatouilles. Prenez garde qu'il ne s'en échappe un, et ne vienne gratter, avec sa bouche, le dedans de votre oreille: il serait ensuite capable d'entrer dans votre cerveau. Sous mon aisselle droite, il y a un caméléon qui leur fait une chasse perpétuelle, afin de ne pas mourir de faim: il faut que chacun vive. Mais, quand un parti déjoue complètement les ruses de l'autre, ils ne trouvent rien de mieux que de ne pas se gêner, et sucent la graisse délicate qui couvre mes côtes: j'y suis habitué. Une vipère méchante a dévoré ma verge et a pris sa place: elle m'a rendu eunuque, cette infâme. Oh! si j'avais pu me défendre avec mes bras paralysés; mais, je crois plutôt qu'ils se sont changés en bûches. Quoi qu'il en soit, il importe de constater que le sang ne vient plus y promener sa rougeur. Deux petits hérissons, qui ne croissent plus, ont jeté à un chien, qui n'a pas refusé, l'intérieur de mes testicules: l'épiderme, soigneusement lavé, ils ont logé dedans. L'anus a été intercepté par un crabe; encouragé par mon inertie, il garde l'entrée avec ses pinces, et me fait beaucoup de mal! Deux méduses ont franchi les mers, immédiatement alléchées par un espoir qui ne fut pas trompé. (Lautréamont, 1988)

Más adelante, el fantasma de Lautréamont volverá a materializarse en incontables versos dalinianos, sobre todo, en aquellos de pulsión caníbal, donde Dalí devora a Gala como acto supremo de amor saturnal, en lo que se torna su tríptico poético más aclamado: La mujer invisible, El amor y la memoria y Me como a Gala, (Sánchez, 2003)

Por entonces, el lema lautreamontiano: "Il est beau comme comme la recontre fortuite sur une table de dissection d'une machine à coudre et d'un parapluie", ya se había convertido en el icono surrealista por antonomasia, representándose hasta la saciedad en todo tipo de imagenes simbólicas, alusivas al célebre pasaje (paraguas y máquinasde coser)

A partir de los años cuarenta, Dalí comienza su etapa Avida Dollars, en la cual, Hollywood empieza a interesarse por él. De resultas de esto, surgirán dos proyectos cinematográficos lautreamontianos: Moontide (1941) (Fig. 1) y The Story of a Wheelbarrow (1948), ambos inconclusos. 
La primera acometida cinematográfica se desenvuelve en un ambiente de pesadilla protagonizada por Bobo, un errabundo marinero que tras matar a un hombre se refugia en una tasca. Una vez dentro, se sumerge en una sucesión de alucinaciones lautreamontianas enumeradas cuidadosamente por Dalí (2003e). En la primera, Bobo contempla atónito una maraña de caóticos cuerpos interconectados por membranas. Inesperadamente, una cuchara irrumpe en escena para tocar el ojo de esa masa informe al tiempo que los cuerpos se contraen como si fuesen un mismo organismo. Aturdido, el marinero intenta salir de la pesadilla; es entonces cuando aparece ante él una mesa de disección con su respectiva máquina de coser y paraguas. A este punto tiene lugar la alucinación numero dos, en la cual dos personajes simulan una calavera virtual. Una calavera que en el delirio numero tres se convierte en armazón de múltiples seres repugnantes. No pudiendo soportar tal visión, Bobo pierde el control y sale a la calle donde la lluvia se convierte en una perspectiva infinita de agujas de máquina de coser. Sin más dilación aparecen en el cielo neblinoso gigantescos paraguas luminiscentes y Bobo reaparece en una plaza presidida por una enorme máquina de coser que tricota ojos. El silogismo es claro, la navaja buñuelesca vertida a la aguja ducassiana. ${ }^{8}$ Una metáfora de la nueva visión surreal representada a través de la salvaje mutilación óptica.

La segunda amenaza cinematográfica la títulará Dalí The Story of a Wheelbarrow, aunque finalmente concluirá llamándose La broutte de chair. La película, inicialmente una colaboración con Paullete Goddard, acabará por convertirse en un proyecto español protagonizado por Ana Magnani (Dalí, 2003f). Clasificada por el autor como el primer filme neomístico, La broutte de chair narra la historia de una mujer paranoica que se enamora de una carretilla de carne. En ella Dalí, sigue a la búsqueda del impacto visual extremo, toda vez invoca nuevas potencias alucinatorias. Ahora, ya embebido en pleno delirio, nos habla de euritmias arcangélicas, mientras cinco cisnes repletos de granadas estallan en un mosaico de vísceras. Luego, más templado, arroja desde lo alto de un edificio seis rinocerontes a la Fontana de Trevi, a fin de que una vez sumergidos, reaparezcan en su lugar seis paraguas negros.

Los postulados teóricos de Dalí carecían de vínculos claros con la cinematografía americana, lo que en cierta medida, devino en el fracaso de sus propuestas. Con todo, el artista seguirá intentando plasmar su peculiar visión de Les Chants de Maldodor, en su prolífica obra plástica. Podríamos afirmar con rotundidad que, el primer intento de introducir a Lautréamont en Hollywood, se debe a Dalí y a su pasión por el poeta.

Tributado el Conde a través de sus escritos, Dalí introducirá en su producción artística algunos de los iconos más representativos de la obra de Lautréamont. Esta forma de relación más íntima -pasada por el filtro paranoico-crítico- derivará, como veremos, en una de las representaciones más fieles y delirantes de este rico diálogo entre ambos genios. 


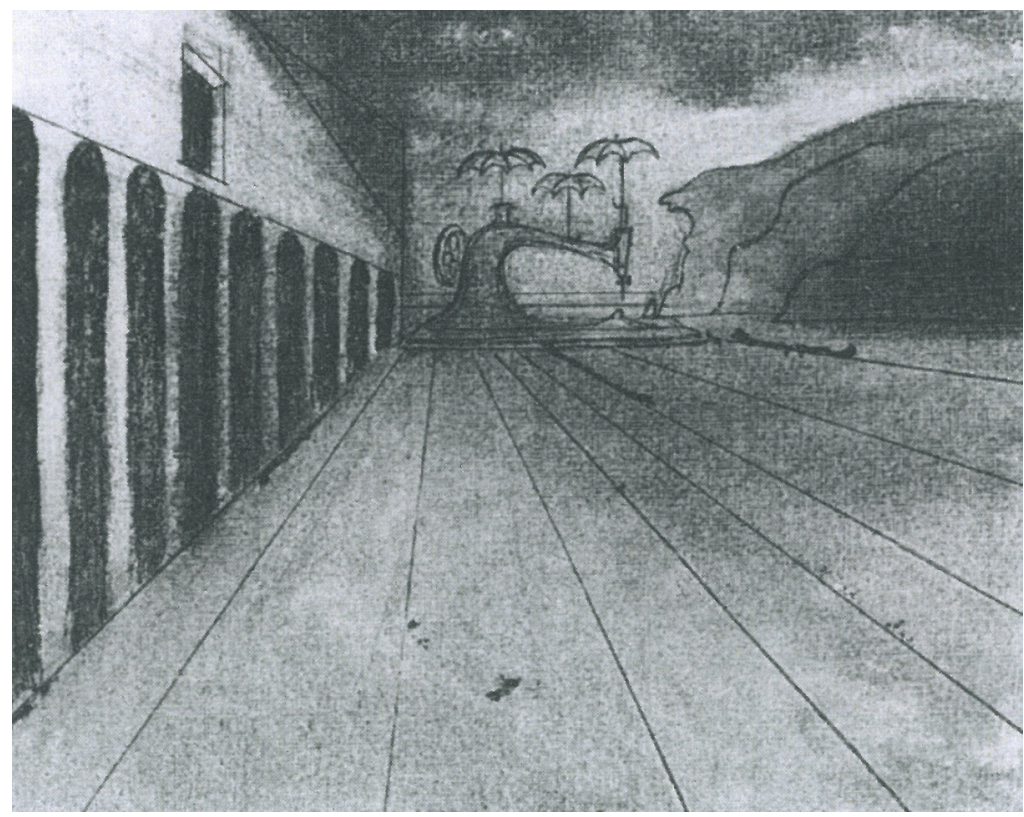

Figura 1. Dalí, Moontide, Escena final, 1941.

\section{Los objetos lautreamontianos: paraguas y máquinas de coser}

La representación de paraguas y máquinas de coser se asentará como uno de los emblemas señeros de Dalí y de los surrealistas. El mundo alucinado de Ducasse parece ser tremendamente adictivo. Esto quizás, sea lo que lleve no sólo a Dalí, sino al grueso de los poetas surrealistas, a innovar menos de lo que se creyó en el campo poético. Lautréamont ya había aportado las bases del perfecto poeta surreal, el reto estaba en idear los nuevos métodos representativos de ese magnífico legado. En ese sentido -y, obviando su falta de originalidad como poeta- Dalí gana enteros, enriqueciendo con sus imágenes ese mundo que parecía relegado exclusivamente al terreno de lo espectral.

El primer intento de mostrarnos ese ámbito de irrealidades, lo encontraremos en el óleo -actualmente desaparecido- ${ }^{9}$, Le miel est plus doux que le sang (1927) (Descharnes, 1984), consumación de un estudio previo del mismo nombre (Fig. 2). El título, puesto en relación con el canto segundo del poeta francés: "O mathématiques sévères, je ne vous ai pas oubliées, depuis que vos savantes leçons, plus douces que le miel, filtrèrent dans mon coeur, comme une onde refraîchisante", muestra la concepción daliniana de Les Chants de Maldoror. ${ }^{10}$ Un universo plagado de putrefacción, ${ }^{11}$ decapitaciones, espermatozoides alados, y agujas de coser alusivas al célebre pasaje, por lo que consideramos, no se sostiene una explicación unicamente lorquiana u "oficial" de la obra (Santos Torroella, 2005), antes bien, se impone una argumentación conciliadora entre el universo lorquiano y el lautreamontiano, en ocasiones mimético. $^{12}$ 


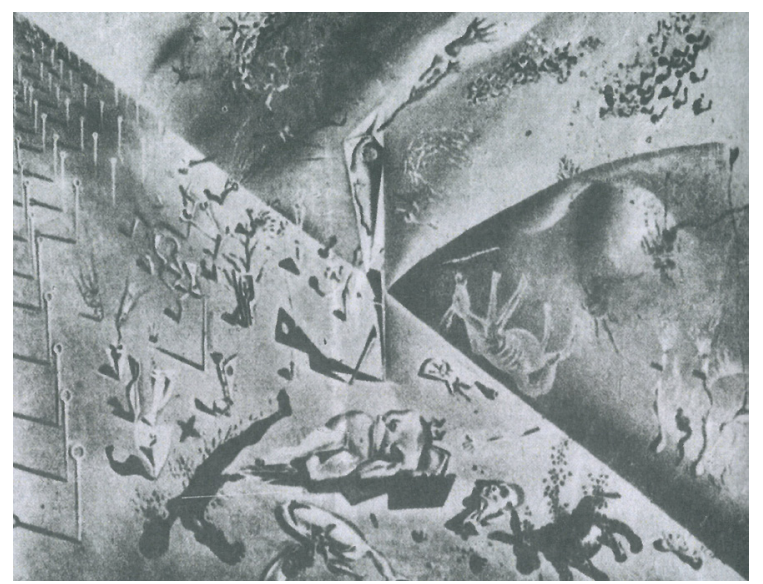

Figura 2. Dalí, Le miel est plus doux que le sang, 1927.

Empeñado en la conquista de París, Dalí confeccionará un corpus iconográfico de entretejidos autobiográficos, en los que el Conde -aún sin rostro- comienza a representarse a través de la figura del paraguas y la máquina de coser. Esto va a iniciarse con el óleo más célebre de Dalí, Le jeu lugubre (1929), para más adelante, mostrarse de manera constante a lo largo de toda su producción artística. La presencia ducassiana como objeto representativo reaparecerá con cierta asiduidad en la obra del artista, véase, Cannibalisme (1934) (Fig. 3) para los grabados de Les Chants de Maldodor, L'enigme d'Hitler (1937), el pabellón Venus' dream (1939), o su concluyente Homenaje a Lautréamont $(1945)^{13}$ Todas ellas, tratadas ampliamente y al detalle en mi tesis doctoral, así como en algunos de los artículos que, en su día, derivaron de ella. ${ }^{14}$

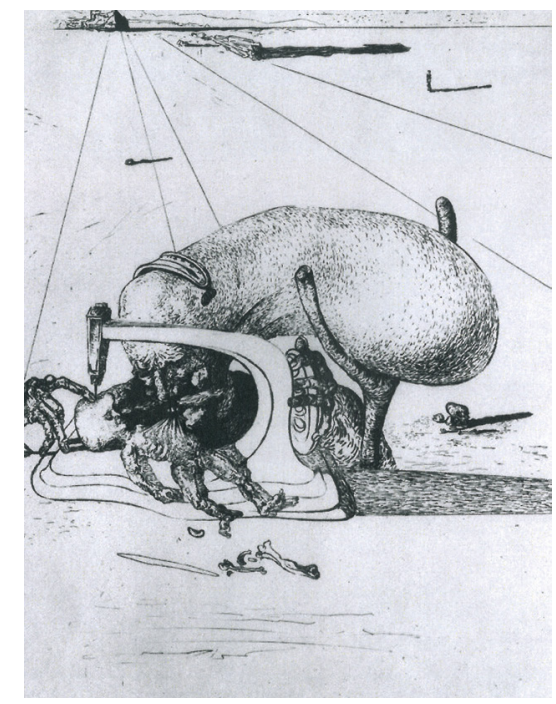

Figura 3. Dalí, Ilustración para Les Chants de Maldoror: Cannibalisme, 1934. 


\section{El bestiario lautreamontiano: del canto del cisne al cerdo como mímesis maldororiana}

Otro elemento de rápida absorción daliniana fue el bestiario de Les Chants de Maldoror, concretamente el cisne y el puerco. Actualmente, parece aceptarse que el cisne es el animal más representativo del movimiento surrealista. Si bien esto es cierto, la pregunta es obligada, ¿de dónde procede este emblema? En principio parece inevitable pensar en pervivencias clásicas, mas, lejos de esto, el cisne surrealista proviene directamente de Lautréamont. La afirmación no es propia, sino de Breton, quien nos aclara en su Dictionaire abregé du surréalisme (1938), cual es la única acepción posible a la entrada del palmípedo: la metamorfosis que precede al asesinato de Dios en la obra de Ducasse; es decir, la transformación de Maldoror en cisne. El pasaje es utilizado por Breton como explicación a su teoría. Por si quedaban dudas, el autor vuelve a insistir en ello al final de la definición, esta vez para aclararnos que el cisne como emblema surrealista surgirá de una de las metamorfosis más celebradas de la obra ducassiana (Breton, 2007). En consecuencia, y a partir de entonces, los surrealistas venerarán a Maldoror a través de la representación del llamado sacro ánade

Expulsado del grupo surrealista y al grito de "Le surréalism, c'est moi", Dalí no dudará en apropiarse de esta emblemática como único y digno heredero del legado surreal (Dalí, 1942). Con ello, y desde el resentimiento, el artista se legitimiza a la vez que estrecha sus vínculos con Maldoror. De hecho, el pintor se referirá a sus ideas como a cisnes que invaden su mente (Dalí, 2003b). Por otra parte, y huyendo de esta abstracción, Dalí utilizará el recurso del ánade en numerosas ocasiones y soportes, véase el artículo La semaine des Parisiens (1973), el guión para su La broutte de chair (1948-52), o la realización de ballets como Don Juan Tenorio (1950) o su Bacchanale (1939)

A estas alturas, el lector ya se habrá percatado de que Dalí, al tratar con Lautréamont, no da nunca puntada sin hilo. Esto va a percibirse en Bacchanale de manera especial, al aunar en un mismo ballet tres de sus más grandes obsesiones: Lautréamont, Luis II de Baviera y Wagner. La obra, una mística salpicada de cisnes, paraguas ducassianos, retratos de Ludwig y música del Tannhäuser, versa sobre el mundo alucinado del monarca bávaro (Descharnes, 1984). Una suerte de delirio de ricas complejidades iconográficas, a galope de los siglos clásicos y contemporáneos, en los que tanto se proyectan templetes rafaelistas como se evoca al masoquismo de Sacher Masoch. Por supuesto, nada mejor para agitar las pasiones del hombre que la música de Wagner, como hilo conductor a esa regresión por la intelectualidad europea, a través de una mente, ciertamente, enferma de romanticismo (Dalí, 2003g)

Alejado de los escenarios y en la intimidad de su estudio, Dalí seguirá proyectando el cisne maldororiano en su obra. Buenos ejemplos de ello son su óleo Cygnes reflétant des éléphants (1937) o su homólogo escultórico Cygnes-éléphants et serpentsPouvant servir de cendrier (1967).

La relación artística de Dalí con el cisne va a estar teñida de múltiples connotaciones maldororianas. Esto también se dejará ver en su cotidianidad más pública de Port Lligat, escenario exhibicionista de su amor palmípedo. Es así, como, ante un recorrido fotográfico por lo que fue el santuario del artista, no ha de extrañarnos 
encontrarnos con dos cisnes disecados presidiendo su biblioteca (Arco, 2003), como tampoco, toparnos de nuevo con esta imagen sobrevolando la cama de los Dalí; dos lugares simbólicos de inspiración daliniana, destinados respectivamente a laboratorio de ideas y fábrica de sueños ${ }^{15}$ (Fig. 4). De todas formas, nada mejor que la voz del artista como explicación a esa pasión desbocada por el sacro ánade. Revivamos, pues, la voz de Dalí, en respuesta a un Soler Serrano inquisitivo:

Joaquín Soler Serrano (en adelante J.S.S). ¿Siguen todavía sus cisnes deslumbrando en la noche las aguas de la bahía de Cadaqués?

Salvador Dali (en adelante S.D). No. La culpa es del turismo, que lo ha llenado todo de lanchas rápidas; y los mataría. Es muy interesante cómo ocurrió la muerte del último cisne. Vino a verme el ex rey de Italia, Humberto de Saboya, y mientras hablábamos llegó un turista negro con un cisne sanguinolento, porque lo había visto volar, creyó que era un animal fantástico y le dio un arponazo que acabó con su vida. Desde entonces no hay cisnes en Cadaqués.

J.S.S. Con lo que a usted le gustaban...

S.D. Sí, a eso de las siete de la tarde, cuando empezaba a anochecer llamaba a mi criado Arturo y le decía: "Arturo, vaya a encender los cisnes». Y es que les ponía unas coronas con lucecitas eléctricas a pilas, y era precioso ver a los cisnes deslizándose por la bahía.

J.S.S. Con ritmo de vals.

S.D. Exactamente. (Soler, 2003)

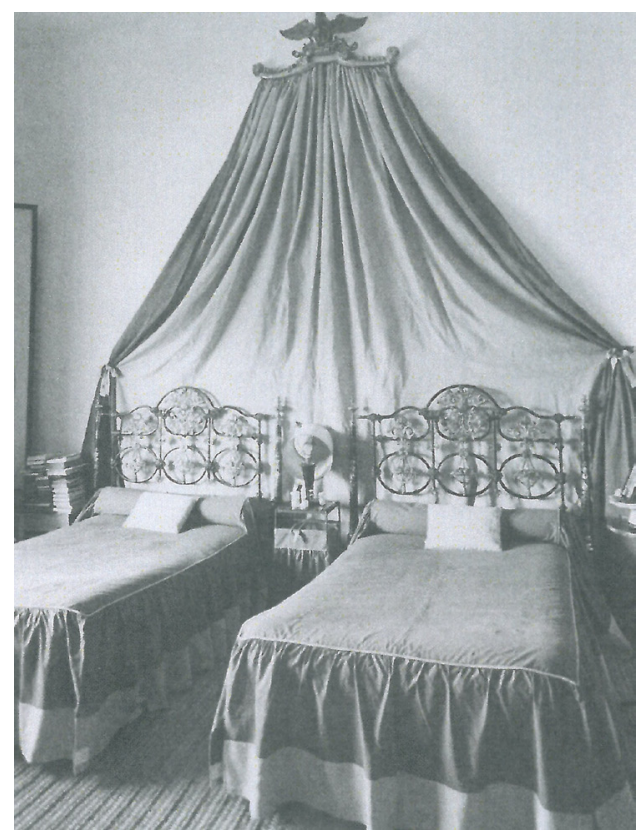

Figura 4. Dormitorio de los Dalí en Port Lligat presidido por un cisne de bronce, c.1972-1975. 
Otra de las bestias ducassianas con las que Dalí tratará, será la transformación de Maldoror en cerdo. Una correlación, ya advertida por Fèlix Fanés en su reciente Prólogo de la obra completa de pintor. Oigámosle como anticipo a esta mímesis: "Menos agresivo, el relato del pintor conserva no obstante los rasgos de rebeldía de aquel que aspiraba, después de que los cerdos le hubieran vomitado encima, a convertirse en uno de ellos (otra metáfora que Dalí, con Lautréamont siempre en su mente, volverá a utilizar años más tarde)" (Fanés, 2003). Ciertamente, el autor, aunque no da ejemplos, acierta de lleno al incidir en esta hipótesis, pues, la ya consabida obsesión daliniana, dará paso a una nueva reapropiación bestiaria. A este punto, debemos recordar, aquella transmutación gozosa de Maldoror en puerco, como primeros compases del mundo inestablede Les Chants de Maldodor. Si Maldoror transmutaba en puerco, Dalí no será menos, pues, en su Carta abierta a Salvador Dalí (1966), se referirá a sí mismo como tal, a propósito del emblema XLV de Alciato (Dalí, 2003h). La correspondencia parece clara, Dalí como genotipo de Maldoror. De nuevo, la única respuesta a este acto surreal, se la debemos agradecer, a un Soler Serrano deseoso de excentricidad:

J.S.S. Eso veo. Que ahora Dali escribe a Dali y le llama puerco.

S.D. Exactamente.

J.S.S. Pero ¿cómo es eso posible?

S.D. Porque me llamo puerco en el buen sentido de la palabra.

J.S.S. ¿Y cuál es ése?

S.D. Mire esta ilustración de mi Carta abierta a Salvador Dali: es un puerco que va hacia el Plus Ultra. Y eso es lo que hacen los puercos. Nunca retroceden, van jesuiticamente de un lado para otro a través de mil viscosidades innumerables, pero dando siempre un paso adelante. (Soler, 2003)

Esta pasión idolátrica por el puerco reaparecerá nuevamente en su proyecto cinematográfico Chaos and Creation (1960) (Fig. 5). El filme, una colaboración con el fotógrafo Philippe Halsman, explora las posibilidades del género documental, en una obra atípica, en la que un Halsman comentarista, se propone desenmarañar el enigma de Salvador Dalí. Entre tanto, éste, en su quehacer pictórico, se dispone a retratar dos modelos junto a una motocicleta rodeada de puercos. El significado de la obra ha sido estudiado por Fèlix Fanés (1995) y posteriormente por Helen Sainsbury (2007). Para ambos, la motocicleta simbolizaría los nuevos medios de la era mecánica, las mujeres el origen de la vida y los cerdos al propio Salvador Dalí. Es fácil presuponer -aunque ninguno de los autores lo explicite- la sombra de Maldoror en ese sentimiento identitario. Por otra parte, la utilización del cerdo como recurso ducassiano ya había sido empleado meses antes en su artículo Cartier-Bresson: Moralities (1960). En dicho artículo, Dalí analiza cuatro de las fotografias más señeras del fotografo francés: Seville (1933), Matisse (1943), Moscow Sports Day (1954), y Holland Pig Farm (1956). Especial consideración merecera esta última, pues, en ella se preámbula su Chaos and Creation, al poner de manifiesto sus futuribles planteamientos porcinos. Entre otras cosas, Dalí nos habla de un proyecto operístico protagonizado por el chillido de cien cerdos degollados; por si fuera poco, a esto habrá de sumársele el ensordecedor ruido de quinientas cincuenta y ocho motocicletas en marcha, todo ello representado en ese 
gran teatro que es la porqueriza. Se podría pensar en esos macabros tenores como en entes maldororianos, en la aniquilación de un Dalí, que en comunión con Maldoror, se siente ciertamente un puerco. Transcurrido el tiempo, esta delectación porcina, irá cobrando matices cada vez más explícitos, hasta convertirse en uno de los mayores tributos que Dalí rendirá a su antihéroe predilecto. No cabía duda, la relación entre el cerdo ducassiano y el daliniano resultaba incuestionable. Dalí se reapropia de la iconografía lautreamontiana y juega a metamorfosearse en los mismos animales en los que acostumbra transmutar Maldoror. Valgan, pues, las siguientes imágenes, como corolario a este juego de identidades.

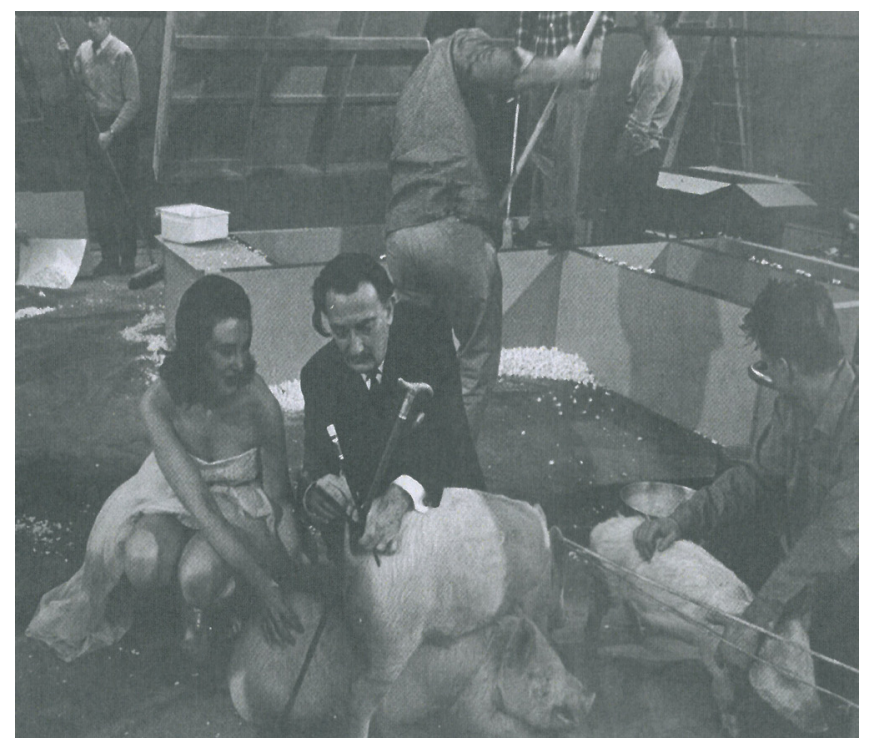

Figura 5. Philippe Halsman y Dalí, Dalí trabajando en su Chaos and Creation, 1960.

\section{Conclusiones}

Iniciábamos este artículo hablando de las "filiaciones perceptibles" de Dalí con Lautréamont. Después de todas estas páginas, parece ineludible constatar ese entrecruzamiento entre lo leíble de la poética lautreamontiana y lo visible de la plástica daliniana. Como una traslación etílica, el emblema verbal del Conde ha germinado -cincuenta años después- en una suerte de ricas emulsiones pictóricas. Estas han resultado ser el principal alimento, no sólo de Dalí, sino del total orbe surrealista. Sabemos que el dardo envenenado de Ducasse ha alcanzado a gran parte de los creadores de aquel París ansiado de nuevas propuestas. Esto se ha dejado entrever, de manera clara, a través de la recepción de su prolífico repertorio iconográfico; una recepción tan variopinta y plural como singularizada en sus planteamientos. 
Dalí -sobrellevado por lecturas obsesivas e intensas- ha de concebirse -junto a Kurt Seligmann y Andre Masson- como el artista surrealista más receptivo a esta imaginería lautreamontiana, siempre alterada a través de pócimas paranoico-críticas. Podremos afirmar, entonces, que la incurrencia del legado ducassiano en la obra del pintor ha sido una constante no sólo cuantitativa sino cualitativa, no sólo explícita sino también implícita. El ancho y largo espectro de sus producciones, por exposición prolongada, se consolida como uno de los mejores ejemplos de esta paragone entre Poesis y Pictura. La longevidad del artista, contraria a la del poeta, le ha permitido convivir con esos poderes representacionales más tiempo que sus colegas surrealistas. Me estoy refiriendo a Kurt Seligmann, Yves Tanguy, Óscar Domínguez, Kay Sage, René Crevel, o Wolffgang Paalen, cuya locura se ha materializado en forma de suicidio. La procurada enajenación surrealista, esa histeria que rompía con las ataduras de la cotidianeidad, parecía un arma de doble filo: por un lado se mostraba extremadamente creadora en lo artístico, por otro, excesivamente destructora en lo vital. Mucho se ha estigmatizado a Lautréamont sobre estos desastres, incluso para muchos -pienso en Leon Bloy- su propia vida había sido ya un ejemplo de disolución y esquizofrenia. De todos modos, lejos de populismos decadentes, el coqueteo con la irrealidad, o, si se quiere, la autosugestión de estar alienado, difícilmente se consuma sin el reactivo de una vida disoluta y hedonista. En este sentido, Dalí debe considerarse una excepción, al experimentar con la locura sin por ello volverse loco. Quizás, y paradójicamente, esta haya sido su mejor baza a la hora de convertirse en el mejor representante del legado lautreamontiano; un planteamiento muy bien medido entre lo real y lo surreal.

Estadísticamente, parece claro que la sombra del conde se acusa más en sus producciones tempranas, e incluso meridianas, que en las de madurez. Salvo en contadas ocasiones, los motivos inherentes a Lautréamont se gestan precoces para posteriormente desarrollarse a lo largo de su extensa carrera. Por lo tanto, concluiremos que la intensidad y presencia iconográfica del universo lautreamontiano disminuye hacia su etapa final.

La relación interartística mantenida por sendos autores ha sido de todo menos usual. Primero porque entre el emisor y el receptor distan más de cincuenta años de diferencia; algo totalmente atípico en cualquier discurso ekphrástico, requerido normalmente de una cierta contemporaneidad entre ambas partes. Segundo, por la intensidad del diálogo, así como por la compenetrabilidad del mismo, pues, no debemos olvidar que Lautréamont sobrevuela el impresionismo, el simbolismo, el fauvismo, el cubismo, el futurismo e incluso el dadaísmo, para eclosionar en aquel primer surrealismo que lo vindicó como deidad y del que Dalí se nutrió. Siendo así, estaríamos ante un caso de correspondencia diacrónica tan atípica como digna de celebrar, en gran parte, obligada por el genio visionario de Lautréamont.

Mi esperanza es que, el presente trabajo, nos ponga sobre la senda de una investigación de mayor envergadura, centrada en las influencias menos detectables de la obra ducassiana en el surrealismo; un trabajo que, de nuevo, obligará a desempolvar los documentos de la Biblioteca Nacional de Francia. Esto sólo pretende ser la primera pieza de un puzzle más complejo. A estas alturas, parece ineludible constatar que la sombra de Lautréamont en Dalí vaya más allá de lo explícito y evidente. 


\section{Referencias}

Ades, D. 2004: El enigma de Hitler, en VV. AA., Catálogo de la exposición, Dalí, celebrada con motivo de su centenario en el Palazzo Grasi de Venecia (12 de septiembre de 2004-16 de enero de 2005), Madrid, La esfera de los libros, págs. 304-311. (Edición a cargo de Dawn Ades).

Arco, M. 2003: Dali al desnudo, en Dalí, Salvador, Obra Completa de Salvador Dalí, Vol. VII, Barcelona, Destino, Fundación Gala-Salvador Dalí, Sociedad Estatal de Conmemoraciones Culturales, págs. 255-341.

Butazzoni, F. 2006: Luz de arriba. Luz de abajo en Revista Bacarola, nos. 68-69, noviembre, págs. 181-186.

Cirlot Valenzuela, L. 2004: Salvador Dalí y sus influencias en AA. VV., Historiografia i crítica al segle XXI, Barcelona, Universitat de Barcelona, págs. 11-19.

Dalí, S. 2003: Carta abierta a Salvador Dalí, Barcelona, Paidós.

Dalí, S. 1960: Cartier-Bresson: Moralities, Art News, 10, February, págs. 38-39.

Dalí, S. 2003c: Confesiones inconfesables en Obra Completa de Salvador Dalí, Vol. II, Barcelona, Destino, Fundación Gala-Salvador Dalí, Sociedad Estatal de Conmemoraciones Culturales, págs. 267-719. (Trad. Hervás, Ramón).

Dalí, S. 1933: De la beauté terrifiante et comestible, de l'Architecture Modern 'Style, Minotaure, 3-4, décembre, págs. 69-76.

Dalí, S. 2003b: Diario de un genio en Obra Completa de Salvador Dalí, Vol. I, Barcelona, Destino, Fundación Gala-Salvador Dalí, Sociedad Estatal de Conmemoraciones Culturales, págs. 925-1185. (Trad. Moura, Beatriz de).

Dalí, S. 1936: Honneur al Objet, Cahiers d'Art, 12, mai, págs. 53-57.

Dalí, S. 1927: Sant Sebastiá, L'Amic de les Arts. Gaseta de Sitges, 16, 31 de julio, págs. 52-54.

Dalí, S. 2003f: La carretilla de carne en Obra Completa de Salvador Dalí, Vol. III, Barcelona, Destino, Fundación Gala-Salvador Dalí, Sociedad Estatal de Conmemoraciones Culturales, págs. 1201-1219. (Trad. Ferrán, Esteve).

Dalí, S. 1973: La Semaine des Parisiens, Paris-Match, 1258, juin, págs. 3-4.

Dalí, S. 1985: Monturiol y Bellini, los dos aún en el fondo del mar, El País, 17 Febrero, pág. 33.

Dalí, S. 2003e: Moontide en Obra Completa de Salvador Dalí, Vol. III, Barcelona, Destino, Fundación Gala-Salvador Dalí, Sociedad Estatal de Conmemoraciones Culturales, págs. 1189-1201. (Trad. Hernández, Pau Joan).

Dalí, S. 1933: Objets Psico-atmosphériques-anamorfiques, Le Surréalisme au Service de la Révolution, 5, 15 mai, págs. 45-48.

Dalí, S. 1931: Objets Surréalistes, Le Surréalisme au Service de la Révolution, Paris, 3, décembre, págs. 16-17.

Dalí, S. 2003d: Poemas y Prosas en Obra Completa de Salvador Dalí, Vol. III, Barcelona, Destino, Fundación Gala-Salvador Dalí, Sociedad Estatal de 
Conmemoraciones Culturales, págs. 155-283. (Trad. Tobar, Felip).

Dalí, S. 1942: Portrait of Salvador Dali, Esquire XVIII, 2, august, págs. 129-131.

Dalí, S. 2003g: Trilogía Bacanal-Laberinto-Sacrificio en Obra Completa de Salvador Dalí, Vol. III, Barcelona, Destino, Fundación Gala-Salvador Dalí, Sociedad Estatal de Conmemoraciones Culturales, págs. 977-992. (Trad. Ferrán, Esteve).

Dalí, S. 2003a: Vida secreta en Obra Completa de Salvador Dalí, Vol. I, Barcelona,

Destino, Fundación Gala-Salvador Dalí, Sociedad Estatal de Conmemoraciones Culturales, págs. 233-925. (Trad. August Jordana, César).

Descharnes, R. 1984: Dali: la obra y el hombre, Barcelona, Tusquets.

Díaz González, E. M. 2010: Aguafuerte y Heliograbado: consideraciones entorno a Les Chants de Maldoror en VV. AA., Catálogo de la exposición, Salvador Dalí. Les Chants de Maldoror. 1934, (del 13 de marzo de 2010 al 31 de diciembre de 2010), Figueres, Distribucións d’Art Surrealista, págs. 145-150. (Comisaria Juliette Murphy).

Fanés, F. 1995: Chaos and Creation: un film inédito de Salvador Dali en Actas del V Congreso de la A.H.C., A Coruña, págs. 19-25.

Fanés, F. 2003: Prólogo en Dalí, Salvador, Obra Completa de Salvador Dalí, Vol.

I, Barcelona, Destino, Fundación Gala-Salvador Dalí, Sociedad Estatal de Conmemoraciones Culturales, págs. 7-43.

Fanés, F. 1999: Salvador Dalí. La construcción de la imagen. 1925-1930, Madrid, Electa.

Fornés, E. 1985: Dalí y los libros, Barcelona, Caja de Barcelona.

Gibson, I. 2004: Dalí joven, Dali genial, Madrid, Santillana.

Gibson, I. 1997: La vida desaforada de Salvador Dalí, Barcelona, Anagrama.

Gibson, I. 1999: Lorca-Dalí. El amor que no pudo ser, Barcelona, Plaza y Janés.

Herrero, R. 2006: Salvador Dali a golpe de Lautréamont en Revista Bacarola, nos. 68-69, noviembre, págs. 216-218.

Hubert, R. R. 1988: Surrealism and the book, Berkeley, University of California Press.

Lautréamont, C. 1988: Poesias en Obra completa bilingüe, Madrid, Akal. (Trad. Alvarez Ortega, Manuel).

Leyra, A. M. 2006: De Cevantes a Dalí. Escritura, imagen y paranoia, Madrid, Fundamentos.

Moure Pazos, I. 2011: El bestiario del Conde de Lautréamont: la invocación daliniana, Santiago, USC.

Moure Pazos, I. 2010: Victimas y verdugos en las ilustraciones de Les Chants de Maldodor de Dali en Anuario del departamento de historia y teoría del arte de la universidad autónoma de Madrid, $\mathrm{n}^{\mathrm{o}}$. 22, págs. 225-239.

Moure Pazos, I. 2011: Sobre el Conde de Lautréamont y el arte surrealista, en Asociación Aragonesa de Críticos de Arte, $\mathrm{n}^{\circ}$. 14, marzo, s/p (edición electrónica). Muñoz D'imbert, S. 2004: Les Chants de Maldoror: la construcción de la máquina 
de lectura en VV. AA., Catálogo de la exposición Dalí: afinidades electivas (del 19 de febrero al 18 de abril de 2004), Barcelona, Fundación Gala-Salvador Dalí, Generalitat de Catalalunya, págs. 351-415. (Edición a cargo de Pilar Parcerisas). Murphy, J. 2010: Les Chants de Maldoror: documentación y proceso creativo, en VV. AA., Catálogo de la exposición, Salvador Dalí. Les Chants de Maldoror. 1934, (del 13 de marzo de 2010 al 31 de diciembre de 2010), Figueres, Distribucións d'Art Surrealista, págs. 139-144. (Comisaria Juliette Murphy).

Parcerisas, P. 2010: Dalí y Ducasse. La sombra de Maldodor en VV. AA., Catálogo de la exposición, Salvador Dalí. Les Chants de Maldoror. 1934, (del 13 de marzo de 2010 al 31 de diciembre de 2010), Figueres, Distribucións d'Art Surrealista, págs. 133-139. (Comisaria Juliette Murphy).

Parcerisas, P. 2009: Duchamp en España, Madrid, Siruela.

Parcerisas, P. 2004: Introducción en VV. AA., Catálogo de la exposición, Dalí: afinidades electivas (del 19 de febrero al 18 de abril de 2004), Barcelona, Fundación Gala-Salvador Dalí, Generalitat de Catalalunya, págs. 16-47. (Edición a cargo de Pilar Parcerisas).

Parcerisas, P. 2006: Lautréamont y el magnetismo de los tiempos modernos en Revista Bacarola, nos. 68-69, noviembre, págs. 151-154.

Parcerisas, P. 2004: Salvador Dalí y Marcel Duchamp: una partida de ajedrez (con Raymond Roussel, Georges Huguet, André Breton, y Man Ray como voyeurs) en VV. AA., Catálogo de la exposición, Dalí: afinidades electivas (del 19 de febrero al 18 de abril de 2004), Barcelona, Fundación Gala-Salvador Dalí, Generalitat de Catalalunya, págs. 110-190. (Edición a cargo de Pilar Parcerisas).

Pérez Andujar, J. 2003: Salvador Dalí: a la conquista de lo irracional, Madrid, Algaba. Rainwater, R. 1997: Au rendez-vous des amis: Surrealist Books and the Beginning of

Surrealist Printmaking in VV. AA., Visionary States: Surrealist Prints from the Gilbert Kaplan Collection, Los Angeles, University of California, pág. 23-44.

Ramírez, J. A. 2003: Dalí: lo crudo y lo podrido, Madrid, Antonio Machado Libros. Rojas, C. 1985: El mundo mítico y mágico de Salvador Dalí, Barcelona, Plaza y Janés.

Rubin, W. 1969: Dada and Surrealist Art, New York, Abrams.

Sánchez Vidal, A. 1988: Buñuel, Lorca, Dalí: el enigma sin fin, Barcelona, Planeta. Sánchez Vidal, A. 2003: Introducción en Dalí, Salvador, Obra Completa de Salvador Dalí, Vol. III, Barcelona, Destino, Fundación Gala-Salvador Dalí, Sociedad Estatal de Conmemoraciones Culturales.

Sánchez Vidal, A. 2009: Transferencias en VV. AA., Un perro andaluz ochenta años después. Luís Buñuel y Salvador Dalí, Madrid, La Fábrica, págs. 73-84.

Sánchez Vidal, A. 1995: Las bestias andaluzas en Catálogo de la exposición: Dalí joven (1918-1930), (Museo Nacional de Arte Reina Sofía, del 18 de octubre de 1994 al 16 de enero de 1995), Madrid, edita el Museo Nacional de Arte Reina Sofía, págs. 253-284. 
Santos Torroella, R. 2005: El primer Dalí. 1918-1929, Valencia, IVAM y Generalitat Valenciana.

Santos Torroella, R. 1984: La miel es más dulce que la sangre. Las épocas lorquiana y freudiana de Salvador Dalí, Barcelona, Seix Barral.

Soler Serrano, J. 2003: Personajes a fondo en Dalí, Salvador, Obra Completa de Salvador Dalí, Vol. VII, Barcelona, Destino, Fundación Gala-Salvador Dalí, Sociedad Estatal de Conmemoraciones Culturales, págs. 1618-1643.

Visa, M. 2003: Dalicedario, Lleida, Milenio.

\section{Notas}

1. Cirlot Valenzuela, Lourdes, "Salvador Dalí y sus influencias" en AA. VV., Historiografia i crítica al segle XXI, Barcelona, Universitat de Barcelona, 2004, pág. 11. Si bien secundamos lo afirmado por Cirlot, nos parece injusto omitir algunas alusiones que, aunque sucintas y epidérmicas, esbozan ya el vínculo Ducasse-Dalí. Por orden cronológico se resaltan las siguientes páginas de libros: Fornés, Eduard, Dalí y los libros, Barcelona, Caja de Barcelona, 1985, pág. 91; Rojas, Carlos, El mundo mítico y mágico de Salvador Dalí, Barcelona, Plaza y Janés, 1985, págs. 234-258; Hubert, Renée Riese, Surrealism and the book, Berkeley, University of California Press, 1988, págs. 205-209; Sánchez Vidal, Agustín, Buñuel, Lorca, Dalí: el enigma sin fin, Barcelona, Planeta, 1988, págs. 281-285; Gibson, Ian, La vida desaforada de Salvador Dalí, Barcelona, Anagrama, 1997, págs. 398-405; del mismo autor, Lorca-Dalí. El amor que no pudo ser, Barcelona, Plaza y Janés, 1999, págs. 125-126; Rainwater, Robert, "Au rendez-vous des amis: Surrealist Books and the Beginning of Surrealist Printmaking" in VV. AA., Visionary States: Surrealist Prints from the Gilbert Kaplan Collection, Los Angeles, University of California, 1997, pág. 26.

2. Parcerisas, Pilar, "Dalí y Ducasse. La sombra de Maldodor"en VV. AA., Catálogo de la exposición Salvador Dalí. Les Chants de Maldoror. 1934, (Del 13 de marzo de 2010 al 31 de diciembre de 2010), Figueres, Distribucións d'Art Surrealista, 2010, págs. 133-139. (Comisaria Juliette Murphy). Si bien éste parece ser el texto definitivo, lo cierto es que, en gran parte de la obra de Pilar Parcerisas, es común el acercamiento a Lautréamont desde el surrealismo o Dalí. A continuación enumeramos las páginas salpicadas por la sombra del conde: "Introducción" en VV. AA., Catálogo de la exposición Dalí: afinidades electivas, op. cit., págs. 28-29; "Salvador Dalí y Marcel Duchamp: una partida de ajedrez (con Raymond Roussel, Georges Huguet, André Breton y Man Ray, como voyeaurs" en VV. AA., Catálogo de la exposición Dalí: afinidades electivas, (Del 19 de febrero al 18 de abril de 2004), Barcelona, Fundación Gala-Salvador Dalí, Generalitat de Catalunya, 2004, pág. 113 (Edición a cargo de Pilar Parcerisas); "Lautréamont y el magnetismo de los tiempos modernos" en Revista Bacarola, Barcelona, nos. 68-69, noviembre 2006, págs. 151-154; Duchamp en España, Madrid, Siruela, 2009, págs. 27-37.

3. Gibson, Ian, Dalí joven, Dalí Genial, Madrid, Santillana, págs. 132-133. "Lorca -como Dalí, apasionado discípulo de Darío en su juventud- tenía un ejemplar de Los raros, y en Impresiones y paisajes (1918), su primer libro, había tomado prestada la evocación que hace Rubén de los perros de Lautréamont, perros que ladran a la muerte bajo la 
luz de la luna. Es posible que Dalí hubiera leído Los raros antes de llegar a Madrid y descubierto allí por sí mismo a Lautréamont. Si no fue así, tal vez Lorca le habló del texto del nicaragüense. Lo que parece seguro, de todas maneras, es que Dalí leyó Los cantos de Maldoror en la Residencia, donde llegó a identificar a Lorca, "el tentador", con el héroe epónimo y rebelde del libro de Ducasse". Asimismo, argumenta, Pérez Andujar, Javier, Salvador Dalí: a la conquista de lo irracional, Madrid, Algaba, 2003, pág. 101. "En su segunda estancia, Dalí encontraría a los alumnos de la Residencia deslumbrados por los Cantos de Maldoror de Lautréamont, un libro del que el grupo surrealista francés se había hecho banderizo".

4. Parcerisas, Pilar, "Introducción”, op. cit., pág. 28. La autora víncula el método paranoicocrítico de Dalí con la obra de Raymond Roussel, en especial con sus obras, Impressions d'Afrique (1910) y Locus Solus (1914): “El método paranoico que Roussel desarrolla con el lenguaje, es sin lugar a dudas, un modelo precursor del método paranoico-crítico de Dalí". Sobre "escritura paranoica", se recomienda la consulta de, Leyra, Ana María, De Cervantes a Dalí. Escritura, imagen y paranoia, Madrid, Fundamentos, 2006. También, relativo al método paranoico-crítico ver la entrada de, Visa, Miquel, Dalicedario, Lleida, Milenio, 2003, págs. 131-137.

5. Sobre lugares frecuentados por Isidore Ducasse ver el magnífico artículo de Granell, Enrique, "Lugares ducassianos" en Revista Bacarola, op. cit., pág. 210.

6. Pérez Andújar, Javier, op. cit., pág. 127. “[...] en la calle donde se alojaba habían vivido en los mismos días Mallarmé y Lautréamont, el autor de aquel libro que toda la Residencia leyó con devoción pagana (y la calle aparecía evocada en Los cantos de Maldoror)".

7. Resulta evidente el vínculo entre Lautréamont y Bataille. Para Dalí, éstos -junto a Sadese convertirán en una alternativa libertadora y manifiestamente antibretoniana. Según Fanés, extensible a su etapa inicial, "Incluso podríamos decir que el pensamiento de Dalí se hallaba mucho más cerca del disidente Bataille que del ortodoxo Breton, aunque por razones probablemente de estrategia se inclinara hacia el segundo, hasta el punto de plegarse a sus caprichos", Salvador Dalí. La construcción de la imagen, Madrid, Electa, 1999, pág. 166. Con razón argumenta Juan Antonio Ramírez, “[ ...] hay otra pulsión en el surrealismo, subterránea, próxima o paralela a la oficial. Es apolítica, más instintiva y sadiana", Dalí: lo crudo y lo podrido, Madrid, Antonio Machado Libros, 2002, pág. 62.

8. Pérez Andújar, Javier, op. cit., pág. 101. Aludiendo a Les Chants de Maldoror, argumenta: "La influencia de esta obra en Dalí y Buñuel resulta visible si se compara el inicio del libro, donde se evoca la imagen de un Maldoror entregado al mal y deseando rebanarle la mejilla a un niño con una navaja, con el inicio de la película Un perro andaluz, inolvidable por la escena en que Luis Buñuel le corta el ojo a una mujer con una navaja de barbero".

9. Dicha obra fue expuesta en el "Saló de Tardor" de Barcelona en 1927 y adquirida por la Duquesa de Lerma. Fue reproducida en el núm. 15 de la revista Ciutat, en Octubre de 1927 para ilustrar el artículo de Dalí "Film arte-Film antiartístico". Desde entonces permanece en paradero desconocido.

10. Sánchez Vidal, Agustín, Buñuel..., op. cit., pág. 282. "Sospecho, incluso, que la expresión más dulce que la miel sufre un cambio de sentido en contacto con el poema y el personaje de Ducasse, conde de Lautréamont [...] Maldoror entona un cántico a las matemáticas, cuyo control frío y exacto contrapone a la pasión de vísceras y arteria [...]". Tambien, Fanés, Fèlix, "Prólogo", op. cit., pág. 29. "[...] que el conocido título del cuadro La miel 
es más dulce que la sangre es una cita de los Cantos [...]"; Parcerisas, Pilar, "Dalí y Ducasse...", op. cit., pág. 133. "Lautréamont y el personaje de Maldoror están presentes tanto en la literatura como en la plástica de Dalí, quien une la paranoia de Lídia de cadaqués y la de Ducasse en el título de la pintura dedicada a Lorca La miel es más dulce que la sangre $[\ldots]$ ".

11. La figura del tiburón, pudiera estar en relación con el Canto II de Les Chants, donde Maldoror se aparea con la hembra del escualo. De todos modos, es una mera conjetura, ya que, no existe documentación que lo verifique.

12. Rojas, Carlos, op. cit., págs. 256-258. El autor es el primero en identificar a Lorca con Maldoror, "La poesía de Lautréamont se cruza con la de Lorca, al igual que el perfil del poeta lo hace con el de Dalí [...]”; Gibson, Ian, Lorca-Dalí..., op. cit., pág. 126. "Todo indica que Lorca-Maldoror vuelve de Cadaqués enamorado de Dalí".

13. Ades, Dawn, "El enigma de Hitler", en VV. AA., Catálogo de la exposición Dalí, op. cit., pág. 304. Relaciona, L'Enigme d'Hitler con Homenaje a Lautréamont, al hilo del paraguas ducassiano: "Dicha representación metafórica-aludiendo a Maldoror y El Angelus- puede aplicarse a El enigma de Hitler, pues el paraguas fálico de Chamberlain, casi idéntico al que aparece en el Homenaje a Lautréamont de Dalí de 1945, pende lánguidamente de una rama de olivo, con una flacidez que recuerda al famoso reloj blando [...]". Es más, vincula el paraguas de L'Enigme d'Hitler con el murciélago, y, a éste con Maldoror: "Dalí equipara, además, el paraguas al murciélago: una fuente de dolor identificada en La Vida Secreta con uno de sus primeros recuerdos de putrefacción, cuando su primo de veinte años disparó a un murciélago en el ala y dio al animal malherido a un Dalí de cinco años; a la mañana siguiente, se despertó y encontró al torturado murciélago todavía vivo pero cubierto de frenéticas hormigas; embargado por la pena, tomó al murciélago en sus manos para besarlo, pero en vez de hacerlo, asestó un desafortunado mordisco a la criatura: un acto sádico digno de Maldoror que podría reflejarse en el segundo murciélago de El Enigma de Hitler, encaramado como un pájaro en el borde derecho del plato e ingiriendo una amorfa ostra blanda [...] Es evidente que Dalí reconoció el potencial maldororeano del murciélago [...]".

14. Vid. Moure Pazos, Iván, El bestiario del Conde de Lautréamont: la invocación daliniana, 2011, USC; asimismo, "Víctimas y verdugos en las ilustraciones de Les Chants de Maldoror de Dalí", Anuario del departamento de historia y teoría del arte de la Universidad Autónoma de Madrid, 22, 2011 y, "Sobre el Conde de Lautréamont y el arte surrealista", ACAA, 14, (2011), (revista digital, s/p).

15. Ya hemos comentado como en ciertas ocasiones, el artista se referirá a su propia inspiración como a cisnes que invaden su mente.

16. Por producciones tempranas, nos referimos a las surgidas entre los años 20 y 40, por meridianas a las realizadas en los años 50 , y por finales o de madurez a las tres últimas décadas. 